\title{
Interleukins with Pulmonary Tuberculosis and the Asthma-Chronic Obstructive Pulmonary Disease Overlap Syndrome
}

\author{
Jun Jun Yeh*1,2 \\ ${ }^{1}$ Ditmanson Medical Foundation Chia-Yi Christian Hospital, Taiwan \\ ${ }^{2}$ Chia Nan University of Pharmacy and Science, Taiwan \\ Received: May 28, 2018; Published: June 08, 2018 \\ *Corresponding author: JunJun Yeh, Ditmanson Medical Foundation Chia-Yi Christian Hospital, Chiayi,Chia Nan University of Pharmacy and Science, \\ Taiwan
}

\section{Mini Review}

Asthma-chronic obstructive pulmonary syndrome (ACOS) is a disorder sharing the components of the asthma and COPD. The ACOS considered as a system inflammation disease. The cytokines such as interleukin-6 (IL-6) [1] and interleukin -10 (IL-10) associated with ACOS [2]. The IL-6 enhancing the inflammation of lung and IL-10 attenuate the inflammation of lung [3,4]. In the ACOS, forced expiratory volume in one second (FEV1\%) predicted was inversely associated with IL-6 level, [5] and cardiovascular disease [6] was associated with an increased IL-6 level [1]. The higher level of IL-6 and lower level IL-10 were found in the ACOS.Therefore the ACOS have the poor lung function and higher frequency of the acute exacerbation [2]. Meanwhile, the ACOS have the higher risk of the neurodegenerative diseases [7] in accordance with these speculations. The incidence of the PTB was higher in the ACOS cohort [8]. The IL- 6 and IL-10 were associated with the active PTB [9]. The lower level of IL-10 was found in the drug-resistant PTB [10]. Meanwhile, the higher level of IL- 6 may be associated with the active PTB progression and is related the radiological severity also [11].

The bacilli loading associated with the chest X-ray [11] and high-resolution computer tomography grading may have a better role for predict the bacilli loading support these findings [12-14]. In versa, the increased IL-10 may have an antibacterial effect on the TB $[15,16]$. The IL-10 as biomarkers of the host response to PTB during convalescence from, and the absence of, active PTB [17]. Moreover, the IL-10 in accordance with the CXR progressive change in initial, recovery and recurrent stage of the PTB $[18,19]$. The statin may attenuate the inflammation of the airway such as asthma [20]. Meanwhile, the COPD cohort with statin use have the lower incidence of the PTB [21]. The report of the up-regulation of the stains by increased level of IL-10 and down -regulation of the IL-6 in the COPD cohort in line with these reports [22]. The statins ame liorated the level of these interleukins may attenuate the inflammation of lung. In addition, statins effective against $\mathrm{TB}$ in macrophages and enhance the activity of the first-line anti-TB regimen in animal study support these speculations also [23].

Therefore, the satins use may have the less incident of the PTB in ACOS.These speculations need more researches for confirmation. However, the role of the IL- 6 and IL-10 in PTB may play a different role in the different stage in different cohort and other cytokines such as interleukin-2(IL-2) or interleukin-4(IL-4) also play a role of the radiological recovery in PTB patients $[9,18,19,24]$. The association of the cytokines, statins with the PTB among the ACOS cohort warrant more researches.

\section{References}

1. Fu Jj, Mc Donald VM, Gibson PG, Simpson JL (2014) Systemic Inflammation in Older Adults With Asthma-COPD Overlap Syndrome. Allergy, Asthma \& Immunology Research 6(4): 316-324.

2. Huang AX, Lu LW, Liu WJ, Huang M (2016) Plasma Inflammatory Cytokine IL-4, IL-8, IL-10, and TNF- $\alpha$ Levels Correlate with Pulmonary Function in Patients with Asthma-Chronic Obstructive Pulmonary Disease (COPD) Overlap Syndrome. Medical Science Monitor: International Medical Journal of Experimental and Clinical Research 22: 2800-2808.

3. De Brito RC, Lucena Silva N, Torres LC, Luna CF, Correia JB, et al. (2016) The balance between the serum levels of IL-6 and IL-10 cytokines discriminates mild and severe acute pneumonia. BMC Pulm Med 16(1): 170 .

4. Zobel K, Martus P, Pletz MW, Ewig S, Prediger M, et al. (2012) Interleukin 6, lipopolysaccharide-binding protein and interleukin 10 in the prediction of risk and etiologic patterns in patients with communityacquired pneumonia: results from the German competence network CAPNETZ. BMC Pulmonary Medicine 12: 6.

5. Cui AH, Zhao J, Liu SX, Hao YS (2017) Associations of IL-4, IL-6, and IL-12 levels in peripheral blood with lung function, cellular immune function, and quality of life in children with moderate-to-severe asthma. Medicine 96(12): e6265. 
6. Yeh JJ, Wei YF, Lin CL, Hsu WH (2017) Association of asthma-chronic obstructive pulmonary disease overlap syndrome with coronary artery disease, cardiac dysrhythmia and heart failure: a population-based retrospective cohort study. BMJ Open 7(10): e017657.

7. Yeh JJ, Wei YF, Lin CL, Hsu WH (2018) Effect of the asthma-chronic obstructive pulmonary disease syndrome on the stroke, Parkinson's disease, and dementia: a national cohort study. Oncotarget 9(15): 12418-12431.

8. Yeh JJ, Wang YC, Kao CH (2016) Asthma-Chronic Obstructive Pulmonary Diseases Overlap Syndrome Increases the Risk of Incident Tuberculosis: A National Cohort Study. PLoS One 11: e0159012.

9. Joshi L, Ponnana M, Sivangala R, Chelluri LK, Nallari P, et al. (2015) Evaluation of TNF- $\alpha$, IL-10 and IL- 6 Cytokine Production and Their Correlation with Genotype Variants amongst Tuberculosis Patients and Their Household Contacts. PLoS ONE 10(9): e0137727.

10. Dmytro B, Mykhailo K, TetyanaKuzhko B (2016) Interleukin-10 gene polymorphism is associated with multi-drug resistant tuberculosis during the intensive phase of standard chemotherapy. International Journal of Mycobacteriology 5: S152-S153.

11. Chowdhury IH, Ahmed AM, Choudhuri S, Sen A, Hazra A, et al. (2014) Alteration of serum inflammatory cytokines in active pulmonary tuberculosis following anti-tuberculosis drug therapy. Molecular Immunology 62(1): 159-168.

12. Yeh J (2018) Validation of a model for predicting smear-positive active pulmonary tuberculosis in patients with initial acid-fast bacilli smearnegative sputum. Eur Radiol 28(1): 243-256.

13. Murthy SE, Chatterjee F, Crook A, Dawson R, Mendel C, et al. (2018) Pretreatment chest $\mathrm{x}$-ray severity and its relation to bacterial burden in smear positive pulmonary tuberculosis. BMC Med 16: 73.

14. Yeh JJ, Yu JK, Teng WB, Chou CH, Hsieh SP, et al. (2012) High-resolution CT for identify patients with smear-positive, active pulmonary tuberculosis. Eur J Radiol 81(1): 195-201.

15. Abdalla AE, Lambert N, Duan X, Xie J (2016) Interleukin-10 Family and Tuberculosis: An Old Story Renewed. Int J Biol Sci 12(6): 710-717.
16. Duell BL, Tan CK, Carey AJ, Wu F, Cripps AW, et al. (2012) Recent insights into microbial triggers of interleukin-10 production in the host and the impact on infectious disease pathogenesis. FEMS Immunology \& Medical Microbiology 64: 295-313.

17. Belay M, Legesse M, Mihret A, Bekele Y, Ottenhoff THM, et al. (2015) Pro- and Anti-Inflammatory Cytokines against Rv2031 Are Elevated during Latent Tuberculosis: A Study in Cohorts of Tuberculosis Patients, Household Contacts and Community Controls in an Endemic Setting. PLoS ONE 10: e0124134.

18. Ndishimye P, Seghrouchni F, Domokos B, Soritau O, Sadak A, et al. (2015) Evaluation of interleukin-10 levels in the plasma of patients with various stages of tuberculosis. Clujul Medical 88(2): 164-167.

19. Mesquita EDD, GilSantana L, Ramalho D, Tonomura E, Silva EC, et al. (2016) Associations between systemic inflammation, mycobacterial loads in sputum and radiological improvement after treatment initiation in pulmonary TB patients from Brazil: a prospective cohort study. BMC Infectious Diseases 16: 368.

20. Miyata R, Bai N, Vincent R, Sin DD, Van Eeden SF (2013) Statins reduce ambient particulate matter-induced lung inflammation by promoting the clearance of particulate matter, $<10$ mum from lung tissues. Chest 143(2): 452-460.

21. Su VY, Su WJ, Yen YF, Pan SW, Chuang PH, et al. (2017) Statin Use Is Associated with a Lower Risk of TB. Chest 152(3): 598-606.

22. Maneechotesuwan K, Wongkajornsilp A, Adcock IM, Barnes PJ (2015) Simvastatin Suppresses Airway IL-17 and Upregulates IL-10 in Patients with Stable COPD. Chest 148(5): 1164-1176.

23. Dutta NK, Bruiners N, Pinn ML, Zimmerman MD, Prideaux B, et al. (2016) Statin adjunctive therapy shortens the duration of TB treatment in mice. J Antimicrob Chemother 71(6): 1570-1577.

24. Iqbal NT, Hussain R, Shahid F, Dawood G (2016) Association of plasma cytokines with radiological recovery in pulmonary tuberculosis patients. International Journal of Mycobacteriology 5(2): 111-119.

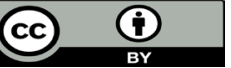

This work is licensed under Creative Commons Attribution 4.0 License

Submission Link: https://biomedres.us/submit-manuscript.php

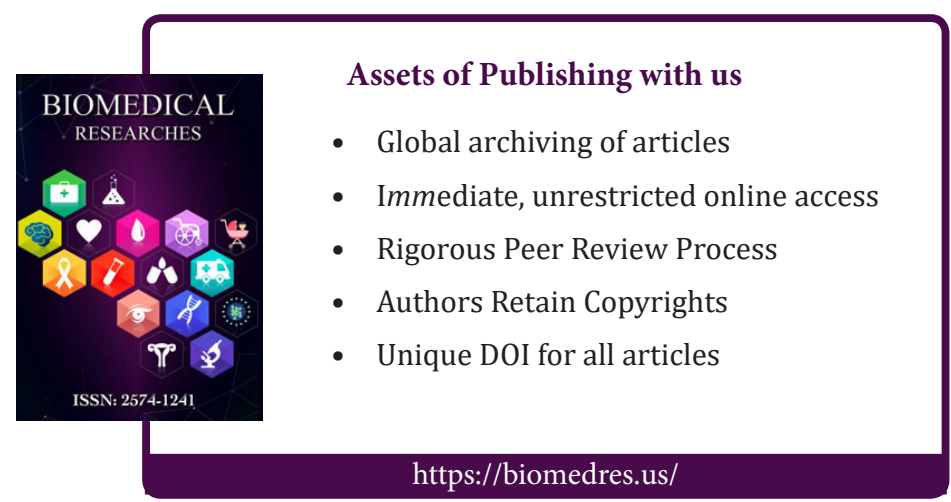

